\title{
Kindergarten Teachers' Perceptions on Young Children's Safety due to Radioactive Contamination
}

\author{
Jinhee Yang*, Yun Park ${ }^{* *}$, Hwayeon Yeo** \\ Dept. of Early Child Education, Korea National University of transportation*, \\ Dept. of Early Child Education, Nambu University ${ }^{* *}$, Dept. of Radiology, Nambu University ${ }^{* *}$

\section{방사능 오염으로 인한 유아 안전에 대한 유치원 교사의 인식} \\ 양진희*, 박 윤**, 여화연** \\ 한국교통대학교 유아교육학과*, 남부대학교 유아교육과**, 남부대학교 방사선학과**
}

\section{Acstract}

The purpose of this study was to examine the impact of the Fukushima nuclear power plant accident of Japan in 2011 on kindergarten teachers' perception on young children's safety due to radioactive contamination. This study analysed the 134 questionnaire forms out of 197 kindergarten teachers in the region of Chungbuk. The findings of the study indicated that the Japanese unclear power plant accident exerted an influence on anxious of kindergarten teachers on young children's safety due to radioactive contamination. In conclusion, kindergarten teacher education are required to improve the safety knowledge of kindergarten teachers and alternative resolution method for young children's safety due to radioactive contamination.

Key word : Radioactive Contamination, Young Children's Safty, Kindergarten Teachers' Perception

\section{요약}

본 연구는 2011년 일본 후쿠시마 원자력 발전소 방사능 누출사고가 방사능 오염으로 인한 유아안전에 대한 유치원 교사의 인식에 미치는 영향을 분석하고, 유아안전 대책마련을 위한 기초자료를 제공하는 데 의의가 있다. 본 연구는 2013년 2월 C도의 공·사립유치원 교사 197명을 대상으로 설문지를 배부하여 회수된 134 명의 자료를 분석하였다.

본 연구의 결과, 일본 원전사고는 방사능 오염으로 인한 유아안전에 대한 교사의 불안감에 영향을 미쳤으나, 방사능 오염으로 인한 유아안전에 대한 유치원 교사들의 안전지식과 대처방안은 낮은 것으로 나타났다. 결론적으로 방사능 오 염으로부터 유아안전을 위한 하나의 방안으로 유아교사교육이 요구되며, 유아안전을 위한 대책 마련이 시급하다.

중심단어 : 방사능 오염, 유아 안전, 유치원 교사의 인식

\section{I. 연구의 필요성 및 목적}

1986년 구소련 체르노빌 원전사고에 이어 2011년
일본 후쿠시마 원전사고는 인간의 생존을 위협하는 방사능 오염에 대한 강한 공포심을 불러일으키고 있 다. 방사능 오염은 핵실험으로 방사성 낙진이나 원자 력 시설에서 방출된 방사성 폐기물 등 인공방사능에 
의해 환경이 오염되는 것을 말하며, 이에 원인이 되는 물질로는 핵분열생성물, 각종 유도방사능을 함유하는 냉각수, 방사성화된 기체, 방사성 물질이 부착된 오물 이나 폐액 등이 있다 ${ }^{[1]}$.

방사능 오염으로 인한 두려움과 공포는 방사능 유 출로 인한 방사능 오염과 관련된 인명피해가 가장 큰 원인으로 작용한다. 미국 환경부 ${ }^{[2]}$, 원자력 문화재단 ${ }^{[3]}$, 월성 원전 환경감시단 ${ }^{[4]}$ 등에 의하면, 1979년 미국 팬 실바니아주 쓰리마일섬 원자력 발전소의 방사능 물질 누출은 사고발생 후 5일 동안 계속되었으며, 사고 반 경 80 킬로미터 내 거주민 200만명이 방사능 물질에 노 출되었다. 이 사고에서 가장 먼저 임산부와 아이들에 게 피난 권고가 이루어졌고, 주변 23개 학교가 폐쇄되 었으나, 지역주민 1 만명 당 약 110 명의 암발생률이 보 고되었다. 또한 1986년 러시아의 체르노빌 원자력 발 전소에서 원자로가 폭발하여 약 10 일간 방사능물질이 누출되었다. 이 사고로 인하여 사고 지점에서 수천 킬 로미터 떨어진 곳까지 방사능물질이 영향을 미쳐 이 로 인한 각종 질병뿐만 아니라, 사산 및 기형아 출산 율이 현저하게 높았으며, 이러한 피해의 영향은 핀란 드 남부, 노르웨이나 스웨덴에까지 이르렀다. 이 사고 후 초기 사망자는 약 30 명 정도 이었으나, 4년 후 약 300 명으로 증가하였으며, 4년 사이 암, 백혈병, 갑상선 질환자의 발생률이 50 퍼센트 이상 증가하였다고 구소 련 당국이 발표했다. 사고 후 누출된 방사능물질은 각 종 과일, 채소, 낙농 제품 등에서도 검출 되었고, 피해 는 지속적으로 발생되고 있다. 이외에도 1987년 브라 질 고이아니아 의료기 도난사고로 인한 방사성 물질 의 누출, 1999 년 일본 도카이무라 사고로 인한 방사능 유출 등으로 심각한 인명 피해가 발생되었다.

이러한 방사능 유출 사고로 인한 자연파괴 및 인명 피해가 세계적으로 급상승 하고 있는 현 시점에서 우 리나라는 1978년 고리 원자력 발전소 1호기가 처음 가 동된 이후 18 기의 원자로를 통해 전체 발전량 $38.9 \%$ 를 공급하고 있는 상황이다 ${ }^{[5]}$.

원자력 발전소가 가동되고 있는 우리나라의 경우, 원전사고로 인하여 누출 된 방사능 물질로 인한 인명 피해에 대하여 무심할 수 없는 입장이다. 실제적으로 후쿠시마 원전사고로 누출된 방사능 물질이 우리나라 로 확산될 가능성에 대해 국민들의 우려는 높고, 또한
각종 토양에 침적되어 농작물에 영향을 미칠 것을 우 려하고 있다. 이는 방사능 물질에 오염된 식품 섭취에 대한 두려움을 낳고 ${ }^{[6]}$, 이에 세계 여러 나라에서는 방 사능 물질에 오염된 식품의 유통을 차단하기 위한 구 제치를 정하여 이를 감시하고 ${ }^{[7]}$ 있는 실정이다. 그러 나 이러한 구제치 등은 방사능 유출로 인한 피해를 최 소화하기 위한 하나의 방안에 지나지 않는다. 보다 근 본적으로 해결해야 할 과제가 국민건강보호 차원에서 체계적이고 구체적이며 장기적으로 이루어져야 한다. 따라서 방사능 오염으로 인한 국민건강보호를 위한 안전문제의 심각성을 이해하고 이에 대한 해결과제의 적극적인 탐색이 요구된다.

본 연구는 일본 원전사고가 방사능 오염으로 인한 유아안전에 대한 교사의 인식에 미치는 영향을 분석 하고, 방사능 오염에 대한 유치원 교사들의 안전지식 을 높임으로써, 방사능 오염으로 인한 유아안전 대책 마련을 위한 기초자료를 제공하는 데 의의가 있다.

\section{II. 연구방법}

\section{1. 연구대상}

본 연구는 2013년 2월에 C도에 소재한 유치원에 재 직 중인 공·사립유치원 교사 197 명에게 설문지를 배부 하여 회수된 134 명의 설문 자료를 분석하였다.

\section{2. 연구도구}

본 연구의 도구인 교사용 질문지는 한국보건사회연 구원(2011) $)^{[8]}$ 의 일본 원전사고가 우리나라 국민의 건 강에 미치는 영향과 대책, 및 김미라와 김효정(2006) 의 '식품 위해물질에 대한 인식도 조사'를 토대로 수 정 - 보완하여 작성되었다. 질문지는 유아교육전문가 3 인, 방사선학 전문가 1 인에게 의뢰하여 내용 타당도를 검토 받았으며, 최종 완성된 질문지는 총 28 문항으로 구성되었다. 질문지 문항구성은 후쿠시마 원전사고와 방사능 오염 5 문항, 방사능 오염으로 인한 유아안전에 대한 교사의 지식 8 문항, 방사능 오염으로 인한 방사 능 오염으로 인한 유아안전에 대한 대처방안 5 문항, 방사능 오염에 대한 유아안전을 위한 교사안전교육실 태 및 요구 5 문항, 방사능 오염에 대한 유아 안전에 대 
"Journal of the Korean Society of Radiology, Volume 7, Number 3"

한 해결과제 5 문항이었으며, 연구대상자의 일반적 특 성을 묻는 기본사항 5 문항이 제시되었다.

\section{3. 자료분석}

수집된 자료는 SPSS WIN 18.0을 이용하여 분석하였 으며, 응답자들의 일반사항에 따라 각 문항별 빈도분 석을 실시하였고 각 변수의 특성에 따른 유의성을 검 증하고자 $x^{2}$-test를 실시하였다.

\section{III. 연구결과 및 해석}

Table 1. General characteristics

\begin{tabular}{|c|c|c|c|c|}
\hline \multirow{2}{*}{ 배경 변인 } & \multirow{2}{*}{ 구분 } & \multicolumn{2}{|c|}{ 빈도(\%) } & \multirow{2}{*}{ 합(\%) } \\
\hline & & 공립 & 사립 & \\
\hline \multirow{2}{*}{ 성 별 } & 남 & & & $0(0)$ \\
\hline & 여 & $69(100)$ & $65(100)$ & 134(100) \\
\hline \multirow{4}{*}{ 연령 } & 20대 & $2(2.9)$ & $29(44.6)$ & $31(23.1)$ \\
\hline & 30대 & $24(34.8)$ & $32(49.2)$ & $56(41.8)$ \\
\hline & 40대 & $37(53.6)$ & $4(6.2)$ & $41(30.6)$ \\
\hline & 50대 & $6(8.7)$ & $0(0)$ & $6(4.5)$ \\
\hline \multirow{3}{*}{ 학력 } & 초대졸 & $3(4.3)$ & $39(60.0)$ & $42(31.3)$ \\
\hline & 대학교 졸 & $38(55.1)$ & $23(35.4)$ & $61(45.5)$ \\
\hline & 대학원 이상 & $28(40.6)$ & $3(4.6)$ & $31(23.1)$ \\
\hline \multirow{4}{*}{ 경력 } & 5년 이하 & $7(10.1)$ & $36(55.4)$ & $43(32.1)$ \\
\hline & 5년 이상 10년 이하 & $10(14.5)$ & $27(39.1)$ & $37(27.6)$ \\
\hline & 10년 이상 15년 이하 & $16(23.2)$ & $2(3.1)$ & $18(13.4)$ \\
\hline & 15년 이상 & $36(52.2)$ & $0(0)$ & $36(26.9)$ \\
\hline 방사능 & 연수경험 있음 & $2(2.9)$ & $0(0)$ & $2(1.5)$ \\
\hline \multirow[t]{2}{*}{ 안전교육 } & 연수경험 없음 & $67(97.1)$ & $65(100)$ & 132(98.5) \\
\hline & 총계 & $69(51.5)$ & $65(48.5))$ & $134(100)$ \\
\hline
\end{tabular}

Table 1 과 같이 연구 대상인 유치원 교사들의 일반 적인 배경을 살펴보면, 성별은 연구대상 모두 여성이 었으며, 연령은 30 대가 $41.8 \%, 40$ 대가 $30.6 \%$ 순으로 많 았다. 학력은 대졸 $45.5 \%$, 초대졸 $31.3 \%$ 순으로 높았 고, 경력은 5 년 이하가 $32.1 \%$ 로 가장 높았다. 방사능 안전교육을 받은 경험에 대해서는 $98.5 \%$ 의 연구대상 이 연수경험이 없다고 응답하였다.
Table 2. Kindergarten teachers' perception on radioactive contamination

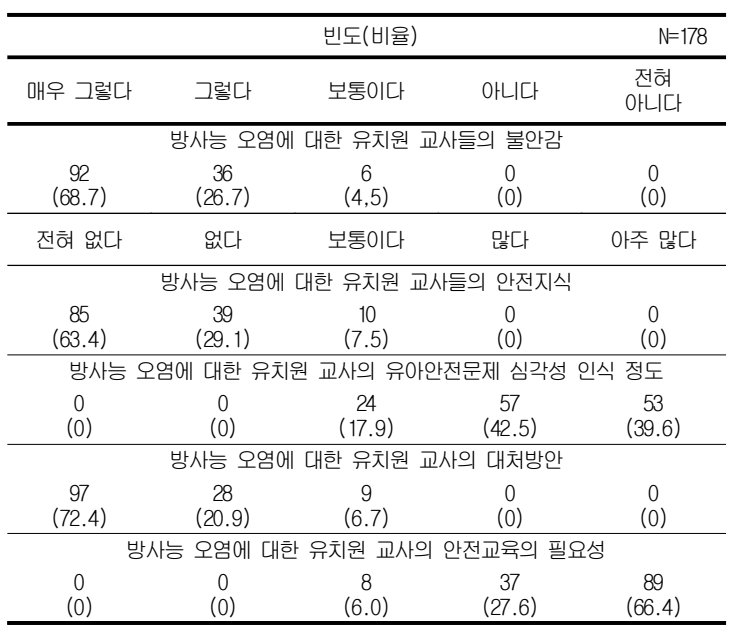

Table 2와 같이 방사능 오염에 대한 유치원 교사들 의 인식조사에서, 유치원 교사들은 방사선 오염에 대 한 불안감은 $95.5 \%$ 가 ‘그렇다와 매우 그렇다'라고 응답 하였다. 방사능 오염에 대한 교사들의 안전지식은 92.5 가 ‘없다와 전혀 없다라고 응답하였다. 방사능 오염 에 대한 유치원 교사의 유아안전문제의 심각성 정도 는 $82.1 \%$ 가 많다와 아주 많다'라고 응답하였으며, 방 사능 오염에 대한 유치원 교사들의 대처방안은 $93.3 \%$ 가 ‘없다와 전혀 없다’라고 응답하였다. 또한 방사능 오염에 대한 유치원 교사의 안전교육의 필요성에 대 해서는 $94 \%$ 가 '많다와 아주 많다'라고 응답함으로써 필요성을 강하게 인식하고 있었다.

Table 3. Kindergarten teachers' safety knowledge on radioactive contamination according to level of education

\begin{tabular}{|c|c|c|c|c|c|c|c|}
\hline \multirow[b]{2}{*}{ 학력 } & \multicolumn{5}{|c|}{ 빈도(비율) } & \multirow[b]{2}{*}{ 합계 } & \multirow{2}{*}{$\begin{array}{l}x^{2} \\
(p)\end{array}$} \\
\hline & $\begin{array}{l}\text { 전혀 } \\
\text { 없다 }\end{array}$ & 없다 & $\begin{array}{l}\text { 보통 } \\
\text { 이다 }\end{array}$ & 높다 & $\begin{array}{l}\text { 아주 } \\
\text { 높다 }\end{array}$ & & \\
\hline 초대 & $\begin{array}{c}26 \\
(61.9)\end{array}$ & $\begin{array}{c}12 \\
(28.6)\end{array}$ & $\begin{array}{c}4 \\
(9.5)\end{array}$ & $\begin{array}{c}0 \\
(0)\end{array}$ & $\begin{array}{c}0 \\
(0)\end{array}$ & $\begin{array}{c}42 \\
(100.0)\end{array}$ & \\
\hline 대학 & $\begin{array}{c}38 \\
(62.3)\end{array}$ & $\begin{array}{c}17 \\
(27.9)\end{array}$ & $\begin{array}{c}6 \\
(9.8)\end{array}$ & $\begin{array}{c}0 \\
(0)\end{array}$ & $\begin{array}{c}0 \\
(0)\end{array}$ & $\begin{array}{c}61 \\
(100.0)\end{array}$ & 3.27 \\
\hline 대학원 & $\begin{array}{c}21 \\
(67.7)\end{array}$ & $\begin{array}{c}10 \\
(32.3)\end{array}$ & $\begin{array}{c}0 \\
(0)\end{array}$ & $\begin{array}{c}0 \\
(0)\end{array}$ & $\begin{array}{c}0 \\
(0)\end{array}$ & $\begin{array}{c}31 \\
(100.0)\end{array}$ & \\
\hline 합계 & $\begin{array}{c}85 \\
(63.4)\end{array}$ & $\begin{array}{c}39 \\
(29.1)\end{array}$ & $\begin{array}{c}10 \\
(7.5)\end{array}$ & $\begin{array}{c}0 \\
0 \\
(0)\end{array}$ & $\begin{array}{c}\cdots \\
0 \\
(0)\end{array}$ & $\begin{array}{c}134 \\
(100.0)\end{array}$ & $d t=4$ \\
\hline
\end{tabular}




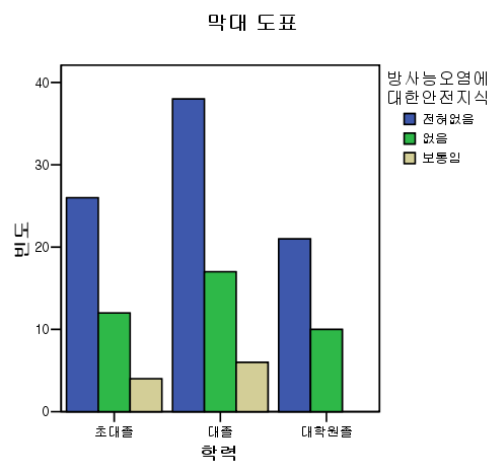

Fig. 1. Kindergarten teachers' safety knowledge on radioactive contamination according to level of education

Table 3과 같이, 유치원 교사의 학력에 따라 방사능 오염에 대한 안전지식 차이가 있는지를 알아본 결과 $x^{2}=3.27(d f 4)$ 로 통계적으로 유의미한 차이가 없는 것 으로 나타났다. 방사능 오염에 대한 안전지식에 대해 성별, 기관유형, 학력, 경력별로 분석하였을 때에도 통 계적으로 유의미한 차이가 나타나지 않았으며, 전반적 으로 방사능 오염에 대한 안전지식은 없는 것으로 나 타났다.

Table 4. Kindergarten teachers' alternative resolution method for young children's safety on radioactive contamination according to level of education

\begin{tabular}{|c|c|c|c|c|c|c|c|}
\hline \multirow{2}{*}{ 학력 } & \multicolumn{5}{|c|}{ 빈도(비율) } & \multirow{2}{*}{ 합계 } & \multirow{2}{*}{$\begin{array}{l}\chi^{2} \\
(p)\end{array}$} \\
\hline & $\begin{array}{l}\text { 전혀 } \\
\text { 없다 }\end{array}$ & 없다 & $\begin{array}{l}\text { 보통 } \\
\text { 이다 }\end{array}$ & 높다 & $\begin{array}{l}\text { 아주 } \\
\text { 높다 }\end{array}$ & & \\
\hline 초대 & $\begin{array}{c}31 \\
(73.8)\end{array}$ & $\begin{array}{c}7 \\
(16.7)\end{array}$ & $\begin{array}{c}4 \\
(9.5)\end{array}$ & $\begin{array}{c}0 \\
(0)\end{array}$ & $\begin{array}{c}0 \\
(0)\end{array}$ & $\begin{array}{c}42 \\
(100.0)\end{array}$ & \\
\hline 대학 & $\begin{array}{c}42 \\
(68.9)\end{array}$ & $\begin{array}{c}14 \\
(23.0)\end{array}$ & $\begin{array}{c}5 \\
(8.2)\end{array}$ & $\begin{array}{c}0 \\
(0)\end{array}$ & $\begin{array}{c}0 \\
(0)\end{array}$ & $\begin{array}{c}61 \\
(100.0)\end{array}$ & 3.52 \\
\hline 대학원 & $\begin{array}{l}24 \\
(77.4)\end{array}$ & $\begin{array}{c}7 \\
\text { (22.6) }\end{array}$ & $\begin{array}{c}0 \\
(0)\end{array}$ & $\begin{array}{c}0 \\
(0)\end{array}$ & $\begin{array}{c}0 \\
(0)\end{array}$ & $\begin{array}{c}31 \\
(100.0)\end{array}$ & \\
\hline 합계 & $\begin{array}{c}97 \\
(72.4)\end{array}$ & $\begin{array}{c}28 \\
(20.9)\end{array}$ & $\begin{array}{c}9 \\
(6.7)\end{array}$ & $\begin{array}{c}0 \\
0 \\
(0)\end{array}$ & $\begin{array}{c}0 \\
(0)\end{array}$ & $\begin{array}{c}134 \\
(100.0)\end{array}$ & $d t=4$ \\
\hline
\end{tabular}

Table 4와 같이, 유치원 교사의 학력에 따라 방사능 오염에 대한 대처방안에서 차이가 있는지를 알아본 결과 $\chi^{2}=3.52(d f=4)$ 로 통계적으로 유의미한 차이가 없 는 것으로 나타났다. 방사능 오염에 대한 대처방안에
대해 성별, 기관유형, 학력, 경력별로 분석하였을 때에 도 통계적으로 유의미한 차이가 나타나지 않았으며, 전반적으로 방사능 오염으로부터 안전하게 보호할 수 있는 대처방안이 없는 것으로 나타났다.

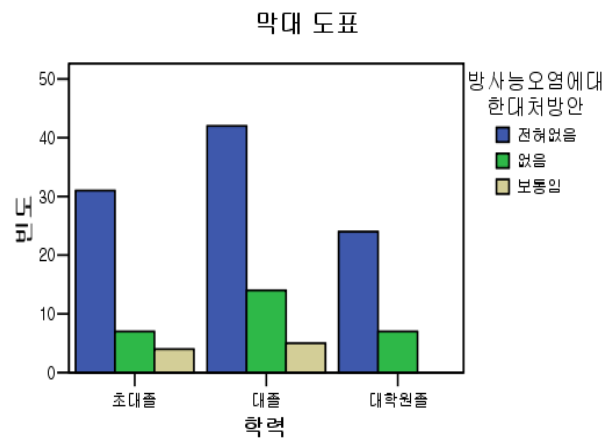

Fig. 2. Kindergarten teachers' alternative resolution method for young children's safety on radioactive contamination according to level of education

Table 5. Kindergarten teachers' perception in young children's safety problem on radioactive contamination according to level of education

\begin{tabular}{|c|c|c|c|c|c|c|c|}
\hline \multirow{2}{*}{ 학력 } & \multicolumn{5}{|c|}{ 빈도(비율) } & \multirow[b]{2}{*}{ 합계 } & \multirow{2}{*}{$\begin{array}{l}x^{2} \\
(p)\end{array}$} \\
\hline & $\begin{array}{l}\text { 아주 } \\
\text { 높다 }\end{array}$ & 높다 & $\begin{array}{l}\text { 보통 } \\
\text { 이다 }\end{array}$ & 낮다 & $\begin{array}{l}\text { 아주 } \\
\text { 낮다 }\end{array}$ & & \\
\hline 초대 & $\begin{array}{c}21 \\
(50.0)\end{array}$ & $\begin{array}{c}15 \\
(35.7)\end{array}$ & $\begin{array}{c}6 \\
(14.3)\end{array}$ & $\begin{array}{c}0 \\
(0)\end{array}$ & $\begin{array}{c}0 \\
(0)\end{array}$ & $\begin{array}{c}42 \\
(100.0)\end{array}$ & \\
\hline 대학 & $\begin{array}{c}20 \\
(32.8)\end{array}$ & $\begin{array}{c}29 \\
(47.5)\end{array}$ & $\begin{array}{c}12 \\
(19.7)\end{array}$ & $\begin{array}{c}0 \\
(0)\end{array}$ & $\begin{array}{c}0 \\
(0)\end{array}$ & $\begin{array}{c}61 \\
(100.0)\end{array}$ & 3.14 \\
\hline 대학원 & $\begin{array}{c}12 \\
(38.7) \\
\cdots \ldots \ldots .\end{array}$ & $\begin{array}{c}13 \\
(41.9) \\
\cdots\end{array}$ & $\begin{array}{c}6 \\
(19.4) \\
\cdots\end{array}$ & $\begin{array}{c}0 \\
(0)\end{array}$ & $\begin{array}{c}0 \\
(0)\end{array}$ & $\begin{array}{c}31 \\
(100.0)\end{array}$ & \\
\hline 합계 & $\begin{array}{c}53 \\
(39.6) \\
\end{array}$ & $\begin{array}{c}57 \\
(42.5) \\
\end{array}$ & $\begin{array}{c}24 \\
(17.9)\end{array}$ & $\begin{array}{c}0 \\
(0)\end{array}$ & $\begin{array}{c}0 \\
(0)\end{array}$ & $\begin{array}{c}134 \\
(100.0)\end{array}$ & $d t=4$ \\
\hline
\end{tabular}

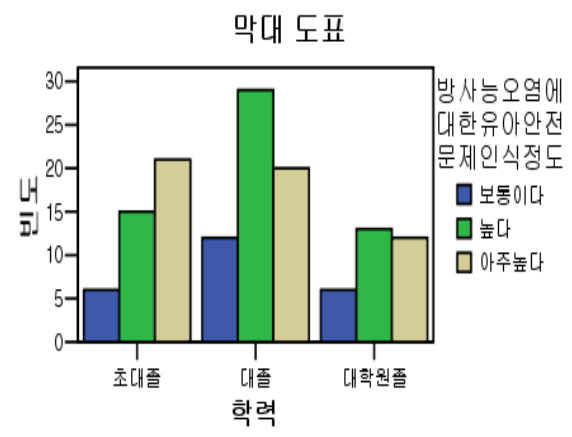

Fig. 3. Kindergarten teachers' perception in young children's safety 
problem on radioactive contamination according to level of education

Table 5과 같이, 유치원 교사의 학력에 따라 방사능 오염으로 인한 유아안전문제에 대한 인식 정도에서 차이가 있는지를 알아본 결과 $\chi^{2}=3.14(d f=4)$ 로 통계적 으로 유의미한 차이가 없는 것으로 나타났다. 방사능 오염으로 인한 유아안전문제에 대한 유치원 교사의 인식 정도는 성별, 기관유형, 경력별로 분석하였을 때 도 통계적으로 유의미한 차이가 나타나지 않았으며, 본 연구의 대상은 일반적인 배경과 관계없이 전반적 으로 방사능 오염으로 인한 유아안전문제의 심각성을 높이 인식하는 것으로 나타났다.

Table 6. Necessity of safety education on radioactive contamination according to level of education

\begin{tabular}{|c|c|c|c|c|c|c|c|}
\hline \multirow[b]{2}{*}{ 학력 } & \multicolumn{5}{|c|}{ 빈도(비율) } & \multirow[b]{2}{*}{ 합계 } & \multirow{2}{*}{$\begin{array}{l}\chi^{2} \\
(p)\end{array}$} \\
\hline & $\begin{array}{l}\text { 매우 } \\
\text { 그럼 }\end{array}$ & 그럼 & $\begin{array}{l}\text { 보통 } \\
\text { 이다 }\end{array}$ & 아님 & $\begin{array}{l}\text { 전혀 } \\
\text { 아님 }\end{array}$ & & \\
\hline 초대 & $\begin{array}{c}29 \\
(69.0)\end{array}$ & $\begin{array}{c}10 \\
(23.8)\end{array}$ & $\begin{array}{c}3 \\
(7.1)\end{array}$ & $\begin{array}{c}0 \\
(0)\end{array}$ & $\begin{array}{c}0 \\
(0)\end{array}$ & $\begin{array}{c}42 \\
(100.0)\end{array}$ & \\
\hline 대학 & $\begin{array}{c}38 \\
(62.3)\end{array}$ & $\begin{array}{c}21 \\
(34,4)\end{array}$ & $\begin{array}{c}2 \\
(3.3)\end{array}$ & $\begin{array}{c}0 \\
(0)\end{array}$ & $\begin{array}{c}0 \\
(0)\end{array}$ & $\begin{array}{c}61 \\
(100.0)\end{array}$ & 3.86 \\
\hline 대학원 & $\begin{array}{c}22 \\
(71.0)\end{array}$ & $\begin{array}{c}6 \\
(19.4)\end{array}$ & $\begin{array}{c}3 \\
(9.7)\end{array}$ & $\begin{array}{c}0 \\
(0)\end{array}$ & $\begin{array}{c}0 \\
(0)\end{array}$ & $\begin{array}{c}31 \\
(100.0)\end{array}$ & \\
\hline 합계 & $\begin{array}{c}89 \\
(66.4)\end{array}$ & $\begin{array}{c}37 \\
(27.6)\end{array}$ & $\begin{array}{c}8 \\
(6.0)\end{array}$ & $\begin{array}{c}0 \\
(0)\end{array}$ & $\begin{array}{c}0 \\
0 \\
(0)\end{array}$ & $\begin{array}{c}134 \\
(100.0)\end{array}$ & $d t=4$ \\
\hline
\end{tabular}

막대 도표

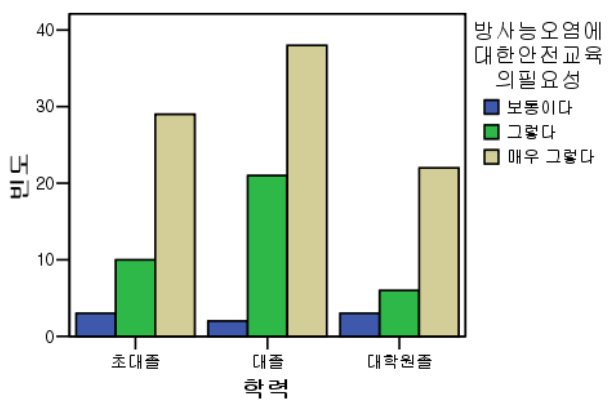

Fig. 4. Necessity of safety education on radioactive contamination according to level of education

Table 6과 같이, 유치원 교사의 학력에 따라 방사능 오염에 대한 안전교육의 필요성에서 차이가 있는지를 알아본 결과 $\chi^{2}=3.86(d f=4)$ 로 통계적으로 유의미한 차 이가 없는 것으로 나타났다. 방사능 오염에 대한 안전 교육의 필요성에서는 성별, 기관유형, 경력별로 분석 하였을 때도 통계적으로 유의미한 차이가 나타나지 않았으며, 전반적으로 방사능 오염에 대한 안전교육의
필요성을 높이 인식하는 것으로 나타났다.

\section{$\mathrm{IV}$. 결론}

본 연구 결과 유치원 교사들의 방사능 오염으로 인 한 유아안전에 대한 불안감은 높은 반면, 방사능 오염 으로 인한 유아안전에 대한 지식은 상대적으로 아주 낮은 것으로 나타났다. 또한 방사능 오염으로부터 유 아 및 자신의 보호에 대한 대처방안은 전혀 없는 것으 로 나타났다. 일본의 후쿠시마 원전사고로 인하여 방 사능물질 오염에 대한 불안감이 높아짐으로써 방사능 오염으로부터 국민건강보호를 위한 법적 규제 및 제 도적 장치 마련에 대한 요구가 높게 나타났다.

본 연구는 일본 후쿠시마 원자력발전소에서 유출된 방사능 오염으로 인한 유아안전에 대한 유치원 교사 들의 불안감이 높았으며, 방사능 오염으로 인한 유아 안전에 대한 유치원 교사들의 안전지식은 낮고, 이에 대한 대처방안이 전혀 없다는 점에서 방사능 오염에 대한 교사교육의 필요성 및 이에 대한 대책마련이 시 급하다는 점을 시사한다.

\section{참 고 문 헌}

[1] 두산동아 편집부, “두산 세계대백과사전”. 두산동아. 2002.

[2] 미국 환경부 - http://www.epa.gov.

[3] 원자력 문화재단 - heep://www.okaea.or.kr.

[4] 월성 원전 환경감시단 - http://www.wolsungnews.com.

[5] 한국산업자원부 - http://www.mocie.go.kr

[6] 양진희, 박윤, 여화연. “방사능 오염식품과 방사선조사 식품에 관한 유치원 부모의 인식 - 2011년 일본 원전사고의 영향력을 중심으로. 한국방사선학회논문지, Vol. 6, No. 6, pp. 435-440. 2012

[7] Gallelli G, Panatoo D, Perdelli F., \& Pellegrino C. Long-term decline of radiocesium concentration in seafood from the Ligurisan Sea(Northern Italy) after Chernobyl, Science of The Total Environment, 196(2): 163-170. 1997.

[8] 한국보건사회연구원. 일본 원전사고가 우리나라 국민의 건강에 미치는 영향과 대책. 2011.

[9] 김효정, 김미라. 식품 위해물질에 대한 인식도 조사. 식품의약품안전청 제출 연구결과 보고서. p. 579. 2006. 